\title{
Ocular injury: Prevalence in different rural population of Bangladesh
}

\author{
Khan AK \\ Gonoshasthaya Somajvittik Medical College, Savar, Dhaka. \\ Email: dristisheba@hotmail.com
}

\begin{abstract}
This population based cross-sectional study was conducted on 8283 persons of all ages in five districts, selected conveniently, to assess the magnitude of ocular injuries, their causes and consequences in rural Bangladesh. Six Upazilas from five districts and from each Upazila one Union was selected randomly. One village, the ultimate cluster, was then selected conveniently from each Union. All people $(\mathrm{n}=8283$ ) in the 8 villages were then surveyed. Out of 8283 population (ranging from 1-120 years) surveyed, $167(2 \%)$ had history and/or evidence of past ocular trauma with a yearly incidence of 6.2 per 1000 per year. Study demonstrated a female predominance with male to female ratio being roughly 4:5. Majority ( $82 \%$ ) had at least one episode of trauma in their life-time with mean age at $1^{\text {st }}$ trauma being 20 years. Nearly $40 \%$ of the traumas were caused by blunt objects followed by penetrating object $(22.3 \%)$ and sharp instrument $(18.1 \%)$ with home being the primary place of occurrence $(55.1 \%)$. Evidence of ocular trauma was found on eye-lid (15\%), conjunctiva (11.4\%) and cornea $(10.2 \%)$ as scars. The older participants ( $\geq 30$ years), females, illiterates, agriculture labors, housewives and household workers were more likely to receive trauma. Majority $(86.8 \%)$ of the subjects received treatment following injury. The median time lapsed between injuries and receiving first treatment was 5 days and that between injury and visiting an eye-specialist was 18 days. Selftreatment and treatment from over-the-counter comprised $45 \%$ and $42.1 \%$ respectively followed by eye-specialists $(25.5 \%)$, village quack $(22.8 \%)$, graduate doctors $(19.3 \%)$ and traditional healers (6.9\%). About $87 \%$ received conservative management, with $12.4 \%$ needing hospitalization. Most of the injured $(92.8 \%)$ and non-injured $(95.2 \%)$ eyes had normal vision before trauma as informed by the respondents. Following trauma, $18 \%$ had impaired, $10.7 \%$ severely impaired vision and about $6 \%$ were blind. Job abstinence due to trauma was $53 \%$ with median wage loss being10 days. The study concludes that point-prevalence of ocular trauma in rural area is around $2 \%$ with blunt objects commonly causing the trauma and one in every 16 trauma-hit case undergo blind. Addressing blindness from ocular trauma, should, therefore, be a priority for eye care programs in rural Bangladesh.
\end{abstract}

\section{Introduction}

Ocular trauma is a major cause of preventable monocular blindness and visual impairment in the world $^{\mathbf{1 , 2}}$. Despite its public health importance, there is relatively less population-based data on the magnitude and risk factors for ocular trauma, specially from developing countries ${ }^{3-5}$. Information on minor ocular injuries requires population-based studies $^{\mathbf{6 , 7}}$. Most studies are based on hospital records, but such data do not accurately indicate the population at risk of sustaining ocular trauma. Useful as they are, they suffer from a bias towards the more serious cases of ocular trauma and underestimate the true magnitude of ocular trauma in the community ${ }^{\mathbf{1 - 3 , 8}}$.

The ocular injuries may range from minor injuries caused by particulate matters to major injuries caused by severe mechanical trauma, irritant chemical substance, fireworks and/or warfare. The current global estimates showed that a total of 1.6 million cases of blindness and some 2.3 million cases of low vision are caused by eye injuries per year. In developing countries around one-third of the monocular blindness results from ocular trauma ${ }^{9}$. Considering the impact of blindness, that the population at risk is usually the productive age groups, and the potential person-days loss of work associated with treatment of the sequel of the trauma, the impact of ocular trauma can be enormous $^{\mathbf{1 0}}$. Studies on ocular trauma worldwide have shown a higher prevalence of trauma in the younger, more productive age groups and among people with lower socioeconomic status and relatively low levels of education ${ }^{\mathbf{3 , 1 1 , 1 2}}$. Few studies have so far looked at ocular trauma from a population perspective in developing countries ${ }^{13,14}$. The burden of blindness in India has been reported to be higher among both rural and urban population $^{6,15-18}$.

Considering the socio-economic characteristics of rural Bangladesh almost similar to that of India, our rural people are generally poor, illiterate, engaged 
in agricultural labor and have less access to eye care services than their urban counterparts, it is likely that rural people may have a greater burden of vision impairment or blindness caused by trauma. Many countries have estimated the magnitude of the problem and formulated strategy of their own to reduce this public health menace. In the absence of a nationwide survey data, Bangladesh has not yet been able to address this issue effectively. Epidemiological studies available in literature on ocular injury conducted in Bangladesh are all (four from Dhaka city and one from Mymensingh) tertiary hospital-based studies ${ }^{\mathbf{1 9 - 2 3}}$ which do not reflect the real picture of the community. The present study is, by far, the first rural population-based study which reports on the prevalence, types of ocular trauma, patterns of eye care utilization after trauma, and vision impairment caused by trauma in rural population of Bangladesh. The findings obtained from the study would be helpful for designing a plan for a nationwide survey of ocular injuries in Bangladesh which might be helpful for formulating ocular injury prevention program in Bangladesh and other low-income countries having similar socio-cultural background.

\section{Materials and Methods}

This population based cross-sectional study was conducted on 8283 persons of all ages in five districts of Bangladesh, selected conveniently to assess the magnitude of ocular injuries, their causes and consequences in rural Bangladesh. By multistage cluster sampling, six Upazilas from five districts and from each Upazila one Union was selected randomly. One village, the ultimate cluster, was then selected conveniently from each Union. Additionally 3 more clusters were selected from two Upazilla of Sherpur District - two were "Char" areas by the river Bhrammaputra and one partly hilly area (dominating tribal people "Garo") at the foot of the Garo Hill with border to Meghalaya state, India. (District-1.Sherpur,villages: Shapmaribetmari, Batkuchi, Chotozhawerchar, Batkuchi; District-2. Dinajpur, village: Durgapara; District-3. Gazipur, village: Tangra; District-4. Cox's Bazar, village: Uttar Rasterpara; and District-5. Pabna, village: Kabashkanda).

Ethical clearance obtained from the Institute of Biological Sciences, University of Rajshahi, as well as from Bangladesh Medical Research Council. The data collection commenced after obtaining informed verbal consent from all participating subjects. As the socio-cultural background of our country is almost similar to Indian subcontinent, a prevalence of $10 \%$ was expected in the present survey similar to the findings reported by Krishnaiah et al $^{\mathbf{1 0}}(10.6 \%)$ in Andhra Pradesh of Southern India. Accordingly the calculated sample size was 3458. But to enhance the validity of the study, the entire study population living in the selected clusters $(n=8283)$ were investigated for evidence of eye injuries ever occurred (prevalence), injury occurred within last 1 month (monthly incidence), 1 year (yearly incidence) and the factors associated with the injuries and visual outcome. Adult subjects were interviewed directly, while in case of minors (younger than 18 years), one of their accompanying parents or guardians were interviewed followed by eye examination of those who have had evidence of ocular trauma.

The participating subjects were interviewed in detail by trained field investigators. Demographic information, including income and detailed ocular history of each subject, was obtained. A structured questionnaire was used to collect information on variables of interest. The first question related to ocular trauma was "Have you ever had any eye injury in your life?" If the answer was 'No', interview was no more proceeded. If the response was 'Yes', further questions about details injury were asked. The response given by the subject was marked by the field investigators against the options on the questionnaire that best correlated with the response. If the response given by the subject did not correlate with any of the items listed in the questionnaire, it was documented separately. Subjects not available for scheduled interview were visited at their home subsequently.

Ocular injury, in the present study, was defined as any injury received in eye ball, periorbital tissue and its adnexa reported by the patient himself, parents or attendant for which care was sought or not. While the demographic data were recorded by paramedics. Patients' interview as regard to trauma, treatment taken, care seeking behavior following trauma were collected by specially trained MBBS doctors or by an ophthalmologist (if felt necessary), usually by the Principal Investigator himself. Information collected included type of injury, its causes, location and intent. Other relevant findings like associated organ injury, past history of ocular injury and any protection measure taken at the time of occurrence were also recorded. Interview was followed by an eye examination by the Principal Investigator or by local assigned ophthalmologist to detect the anatomical location, severity, consequence of the injury including measurement of visual acuity by Snellens Chart.

Clinical features were recorded as extra ocular and ocular findings (anterior segment and posterior segment). Clinical grading of the injury was 
categorized as 'severe' or 'mild'. Severe injuries were corneal ulcer (unless very small like pinhead and away from pupillary area), traumatic cataract, penetrating corneal foreign body (involving $>1 / 3$ of corneal thickness), corneal rupture, iridodialysis, iris prolapse, dislocated lens, scleral rupture, corneal blood stain, macular/retinal damage, hyphaema and full thickness lid injury and lid with canaliculi injury. Mild injuries were lid edema, bruis and laceration (not full thickness), superficial corneal foreign body (involving $<1 / 3$ corneal thickness), conjunctival tear, subconjunctival hemorrhage. Injuries with multiple diagnoses, those with any 'severe' component were categorized as 'severe' and those without any 'severe' component, though multiple, were considered 'mild'. Participants were asked whether hospital admission was needed. If so, for how many days. Types of treatment given: Medical, surgical or both. Visual Acuity measurement: Patients' visual acuity was categorized according to WHO definition of impairment of vision. Accordingly 6/6-6/9 was considered as normal vision, $6 / 12-6 / 24$ as impairment of vision, $6 / 36-3 / 60$ as severe impairment of vision and $<3 / 60$ was considered blind. Incidence rate of ocular trauma was estimated in this study, using the injuries reported to have occurred in the year preceding the interview as the numerator and the number of subjects interviewed as the denominator. Abstinence from job due to injury was calculated recalling from the day of incidence of injury till joining the job.

Statistical analysis: Data were processed and analyzed using computer software SPSS (Statistical Package for Social Sciences). The test statistics used for analysis of data were Chi-square Probability Test (for comparison of data presented in categorical scale) and Student's t-test (for comparison of data presented in quantitative scale). Risk of developing eye injury was estimated using Odds Ratio along with $95 \%$ confidence interval for population at risk. For any analytical test the level of significance is 0.05 and p-value $<0.05$ was considered significant.

\section{Result}

Demographic characteristics: Of the 8283 population (ranging from 1-120 years) surveyed for ocular trauma in the rural area of 5 Districts of Bangladesh, 167(2\%) had history and/or evidence of past ocular trauma. The peak age incidence of ocular trauma was observed to be $3^{\text {rd }}$ decade of life. Thereafter the vulnerability for ocular injury decreases with increasing age. The median age of the participants having ocular injury was significantly higher compared to those without ocular injury ( $40.5 \pm 1.5$ vs. $26.5 \pm 0.2$ yrs, $\mathrm{p}<0.001)$. The risk of getting ocular trauma was almost 4 times $(95 \%$ of $\mathrm{CI}=2.8-5.5)$ higher among participants $\geq 30$ years old compared to those below 30 years (table I). No significant association was observed between sex and ocular injury, although females were somewhat higher in the injured group than those in the non-injured group $(\mathrm{p}=0.198)$ (table I). Comparison of marital status between participants with and without ocular injury is shown in table I. Married participants tend to receive ocular injury more often than their nonmarried counterparts or participants below marriageable age $(p=0.002)$. The risk of having ocular trauma in married population was observed to be $2.8(95 \% \mathrm{CI}=1.4-5.5)$ fold higher than their non-married counterparts or participants below marriageable age. In terms of occupation, farmers, agriculture labors, housewives and participants engaged in household works were more vulnerable to have ocular injury than the participants engaged in other occupations (industry labor, service-holder, businessmen and others) with odds of getting trauma in the former group of occupants was more than 3(3.1 - 4.6) times as likely to receive ocular trauma as the later group of occupants $(\mathrm{p}<0.001)$ (table I). Illiterates and subjects having no formal education were $1.7(95 \%$ of $\mathrm{CI}=1.3-2.3)$ times more prone to have the trauma than their literate counterparts $(\mathrm{p}<0.001)$ (table I).

Table I: Association between demographic characteristics

\begin{tabular}{|c|c|c|c|c|}
\hline \multirow[b]{2}{*}{$\begin{array}{l}\text { Demographic } \\
\text { characteristics* }\end{array}$} & \multicolumn{2}{|c|}{ Group } & \multirow[b]{2}{*}{$\begin{array}{l}\mathrm{p}- \\
\text { value }\end{array}$} & \multirow[b]{2}{*}{$\begin{array}{c}\text { Odds Ratio } \\
\text { (95\% CI of } \\
\text { OR) }\end{array}$} \\
\hline & $\begin{array}{c}\text { Ever } \\
\text { injured } \\
(\mathrm{n}=167)\end{array}$ & $\begin{array}{l}\text { Never } \\
\text { injured } \\
(\mathrm{n}=8116)\end{array}$ & & \\
\hline \multicolumn{5}{|l|}{ Age (years) } \\
\hline$<30$ & $47(28.2)$ & $5000(61.6)$ & \multirow{2}{*}{$<0.001$} & \multirow{2}{*}{$\begin{array}{c}3.98(2.87- \\
5.52)\end{array}$} \\
\hline$\geq 30$ & $120(71.8)$ & $3116(38.4)$ & & \\
\hline $\begin{array}{l}\text { Median } \pm \text { SEM } \\
\text { Sex }\end{array}$ & $40.5 \pm 1.5$ & $26.5 \pm 0.2$ & & \\
\hline Male & $74(44.3)$ & $4005(49.3)$ & \multirow{2}{*}{0.198} & \multirow{2}{*}{$\begin{array}{c}\text { Not } \\
\text { applicable }\end{array}$} \\
\hline Female & $93(55.7)$ & $4111(50.7)$ & & \\
\hline \multicolumn{5}{|l|}{ Marital status } \\
\hline Married & $140(83.8)$ & $4690(57.8)$ & \multirow{3}{*}{$<0.001$} & \multirow{2}{*}{$3.7(2.5-5.7)$} \\
\hline Unmarried & $27(16.2)$ & $3426(42.2)$ & & \\
\hline \multicolumn{4}{|l|}{ Occupation } & \\
\hline $\begin{array}{l}\text { Farming, agriculture } \\
\text { Labor \& Housewife }\end{array}$ & $142(85.0)$ & $6136(75.5)$ & \multirow[t]{3}{*}{0.005} & \multirow[t]{3}{*}{$1.8(1.2-2.8)$} \\
\hline Other occupants & $25(15.0)$ & $1980(24.5)$ & & \\
\hline Educational level & & & & \\
\hline Illiterate or no- & $80(47.9)$ & $2873(35.4)$ & \multirow{2}{*}{$<0.001$} & \multirow{2}{*}{$1.7(1.2-2.3)$} \\
\hline $\begin{array}{l}\text { formal education } \\
\text { Literate }\end{array}$ & $87(52.1)$ & $5243(64.6)$ & & \\
\hline
\end{tabular}

Figures in the parentheses denote corresponding percentage *Data were analyzed using Chi-square $\left(\chi^{2}\right)$ Test.

Trauma-related profile: Majority (82\%) of the respondents with ocular trauma received at least one episode of trauma in their life-time with mean age at $1^{\text {st }}$ trauma being 20 years. Over $30 \%$ of the subjects with trauma had the incident in the last 1 
year with right eye being more often injured $(22.8 \%)$ than the left one $(7.8 \%)$, while the incident of trauma in the month preceding the interview was $7.8 \%$ (right eye $5.4 \%$ and left eye $2.4 \%$ ). The home was the primary place of occurrence $(55.1 \%)$ followed by agriculture field (21.6\%) (Table II). In terms of causes of trauma, blunt object was highest in frequency $(39.1 \%)$ followed by penetrating object $(22.3 \%)$, sharp instrument $(18.1 \%)$ and others $(18.1 \%)$. Chemicals and heat rarely caused the injury. Self-inflicted injury (while working or playing) comprised 42.5\%, accidental and homicidal injuries $28.1 \%$ and $18 \%$ respectively. Twelve percent gave the history of associated injuries elsewhere in the body. The white part was most frequently involved $(50.3 \%)$ followed by eyelid (23.4\%) and black part (19.8\%) (Table II).

Table II: Distribution of ocular trauma cases by trauma-related profile $(\mathrm{n}=167)$

\begin{tabular}{|c|c|c|}
\hline Trauma-related profile & $\begin{array}{c}\text { Frequency } \\
(\%)\end{array}$ & $\begin{array}{c}\text { Mean } \pm \text { SEM } \\
\text { (range) }\end{array}$ \\
\hline \multicolumn{3}{|l|}{ Frequency of trauma } \\
\hline One time & $137(82.0)$ & \\
\hline Two times & $25(15.0)$ & ----- \\
\hline Three to four times & $5(3.0)$ & \\
\hline Age at $1^{\text {st }}$ trauma $(y r s)$ & & $20 \pm 1.6(5-82)$ \\
\hline Received trauma in last 1 year & $51(30.6)$ & ---- \\
\hline Received trauma in last 1 month & $13(7.8)$ & ----- \\
\hline \multicolumn{3}{|l|}{ Places of occurrence } \\
\hline Home & $92(55.1)$ & \\
\hline Agriculture field & $38(21.6)$ & \\
\hline Road & $12(7.2)$ & ----- \\
\hline Factory & $4(2.4)$ & \\
\hline Play-field/Amusement & $11(6.7)$ & \\
\hline Others & $12(7.2)$ & \\
\hline \multicolumn{3}{|l|}{ Causes of trauma } \\
\hline Blunt object & $65(39.1)$ & \\
\hline Sharp instrument & $30(18.1)$ & \\
\hline Penetrating object & $37(22.3)$ & \\
\hline Chemicals & $1(0.6)$ & \\
\hline Heat & $3(1.8)$ & \\
\hline Others & $30(18.1)$ & \\
\hline \multicolumn{3}{|l|}{ Nature of injury } \\
\hline Self-inflicted & $71(42.5)$ & \\
\hline Accidental & $47(28.1)$ & \\
\hline Assault & $25(18.0)$ & \\
\hline Others & $19(11.4)$ & \\
\hline Associated injury & $20(12.0)$ & \\
\hline \multicolumn{3}{|l|}{ Parts of eye involved } \\
\hline White part & $84(50.3)$ & \\
\hline Eye-lid & $39(23.4)$ & \\
\hline Black part & $33(19.8)$ & \\
\hline Not known & $11(6.6)$ & \\
\hline
\end{tabular}

Parts of eye involved: Evidence of ocular trauma on eye-lid was observed in $15 \%$ cases as scar. Scars on conjunctiva and cornea were found in 11.4 and $10.2 \%$ cases respectively. Other parts of eye were seldom injured as evident from the data presented in table III. Ten patients out of 167 with evidence of ocular trauma underwent blind. Of them 5 were phthisis bulbi, 3 had corneal scar, 1 traumatic cataract and 1 surgical anophthalmia. Only 4\% ocular trauma cases took protection measure before occurrence of injury.
Table III: Parts of eye involved in the injury $(\mathrm{n}=167)$

\begin{tabular}{lcc}
\hline Evidence of ocular injury & Frequency & Percentage \\
\hline Scar on eyelid & 25 & 15.0 \\
Scar on conjunctiva & 20 & 11.9 \\
Scar on cornea & 19 & 11.4 \\
Trauma related spot on iris & 2 & 1.2 \\
Traumatic cataract & 9 & 5.4 \\
Sub-luxation of lens & 4 & 2.4 \\
phthisis bulbi & 5 & 3.0 \\
Surgical anophthalmia & 1 & 0.6 \\
Others & 5 & 3.0 \\
\hline
\end{tabular}

* Total will not correspond to $100 \%$ for multiple response

Care-seeking behavior: Majority (86.8\%) of the subjects received treatment following injury. The median time lapsed between injury and receiving first treatment was 5 days (range: 1-360 days), while the median time lapsed between injury and first treatment with an eye-specialist was 18 days (range: 1-480 days). Nearly half $(45.5 \%)$ of the subjects tried self-treatment, $42.1 \%$ received treatment from over-the-counter, $25.5 \%$ from eyespecialist, $19.3 \%$ from graduate doctors, $35.2 \%$ from quack, and $6.9 \%$ from Kabiraj (table IV)

Table IV: Distribution of patients by their care-seeking behavior $(\mathrm{n}=167)$

\begin{tabular}{lcc}
\hline Care seeking behavior & $\begin{array}{c}\text { Frequency } \\
(\%)\end{array}$ & $\begin{array}{c}\text { Median } \pm \\
\text { SEM } \\
\text { (range) }\end{array}$ \\
\hline Received care & $145(86.8)$ & \\
Time lapsed between injury and $1^{\text {st }}$ & & $5.0(1-360)$ \\
treatment (days) & & $18.0(1-480)$ \\
Time lapsed between injury and & & \\
specialist treatment (days) & & \\
Care seeking pattern & & \\
Self-treatment & $66(45.5)$ & \\
Over the counter & $61(42.1)$ & \\
Eye specialist & $37(25.5)$ & \\
Quack (Both allopath \& homeopath) & $51(35.2)$ & \\
Graduate doctor & $28(19.3)$ & \\
Indigenous healer (Kabiraj) & $10(6.9)$ & \\
\hline
\end{tabular}

* Total will not correspond to $100 \%$ for multiple response

Management and outcome: Of total 167 subjects, 145 received care and of them about $87 \%$ received conservative management, $7.6 \%$ operative management and $5.5 \%$ both. Eighteen (12.4\%) needed hospitalization following the incident. Most of the injured (92.8\%) and non-injured (95.2\%) eyes had normal vision before trauma as informed by the respondents. On examination two-thirds $(65.9 \%)$ of the injured eye had normal visual acuity, $18 \%$ impaired and $10.7 \%$ severely impaired vision. Over 5\% were blind (table V). Of the 167 patients, 89(53\%) informed that they had to be absent from their jobs due to ocular trauma. The median working days lost due to trauma was 10 days and the minimum and maximum days lost were 0 and 365 days respectively. 
Table V: Distribution of patients by management and its outcome

\begin{tabular}{lcc}
\hline Management given and its outcome & $\begin{array}{c}\text { Frequency } \\
(\%)\end{array}$ & $\begin{array}{c}\text { Mean } \pm \text { S } \\
\text { EM }\end{array}$ \\
\hline Type of treatment $(\mathrm{n}=145)$ & & \\
Conservative & $126(86.9)$ & --- \\
Operative & $11(7.6)$ & --- \\
Both & $8(5.5)$ & --- \\
Needed hospitalization $(\mathrm{n}=167)$ & $18(10.78)$ & --- \\
Duration of hospitalization (days) & --- & $7.6 \pm 1.6$ \\
Vision before trauma (Injured eye) & & \\
Normal & $155(92.8)$ & --- \\
Defective & $12(7.2)$ & \\
Vision before trauma (Other eye) & & \\
Normal & $159(95.2)$ & --- \\
Defective & $8(4.8)$ & \\
Present status of vision in the injured eye & & \\
$6 / 6-6 / 9$ (normal) & $110(65.9)$ & --- \\
6/12 - 6/24 (impairment of vision) & $30(18.0)$ & --- \\
$6 / 36-3 / 60$ (severe impairment of vision) & $17(10.17)$ & --- \\
$<3 / 60$ (blind) & $10(5.98)$ & --- \\
\hline
\end{tabular}

Causal agents: Diverse agents/instruments were implicated in the causation of injuries. Of them blunt instruments like bamboo sticks, wood and hand-blow were predominant. Other less frequently implicated blunt agents/instruments were brickstone, vegetables, iron-rod, toy, cow-tail, jute stick, etc. The sharp-cutting or penetrating agents were paddy spikes, sharp margin of the paddy leaves, blade, knife, broken glass, wire and bite by hen etc. The chemicals and liquids were lime and hot water. The sand dust and particulate matters were seldom reported.

\section{Discussion}

As this is, by far, the first population-based study on ocular injury in Bangladesh, this report provides valuable information about the extent of ocular trauma in its rural community.

Prevalence of ocular trauma: The prevalence of ocular trauma of any kind was $2 \%$ among population ranging from $1-120$ years of ages. This is lowest prevalence rate of ocular trauma ever reported in the literatures. The nearest figure to this finding was $2.4 \%$ in Delhi Slum study ${ }^{24} ; 3.9 \%$ in South India by Dandona et $\mathrm{al}^{6} ; 4.5 \%$ in South India by Aravind study ${ }^{7} ; 5 \%$ in Singapore Malay Urban Eye study ${ }^{25}$, while the rates as high as $10.6 \%$ in Andhra Pradesh study on rural population of all ages $^{\mathbf{6}}, 13.3 \%$ in Tehran study by Hashemi et $\mathrm{al}^{26}, 14.4 \%$ in the Baltimore study ${ }^{1}$ and $19.8 \%$ in the Beaver Dam study ${ }^{10}, 21.1 \%$ in a study in Australia ${ }^{4}$ have also been reported. Overall, the prevalence rates reported in the literatures vary greatly. The wide variation in the rates of ocular trauma could be attributed to the different age compositions of the study populations. Other factors could be the level of education, health service coverage, rate of employment, population density, economic and industrial development, the use of safety wear in the workplace and the economic status as a determinant of occupation type ,27-29 $^{\text {. }}$

The possible explanation for low prevalence of ocular trauma in this study might be an underestimation of the true rate, as data were collected by recall method, the study was conducted in remote villages with least possible risk of trauma because of life-style, occupation and involvement of all age groups. The young children and elderly are at least risk of acquiring the trauma ${ }^{25}$.

Incidence of ocular trauma: The incidence rate of ocular trauma was estimated using only those injuries that occurred during the year preceding interview as were done in New England Study ${ }^{30}$ and Baltimore Eye Survey ${ }^{1}$. Previous populationbased studies of ocular trauma have reported incidence rates based on hospitalizations and emergency department and ophthalmologic visits $^{11,31,32}$. The incidence rates varied from 9.75 per 1000 for any medically treated injuries among aged 18 years and older in New England to almost 0.29 per 1000 for hospitalizations in which ocular trauma was either the principal or secondary discharge diagnosis ${ }^{\mathbf{3 0 , 3 1}}$. The data reported here are based on the lifetime prevalence of any ocular injuries and are, therefore not comparable to incidence rates based on more severe injuries. In this study the incidence of any ocular trauma was 6.2 per 1000 per year irrespective of age of the participants. For calculating yearly incidence of any acute disease/health-events, the denominator must be a mid-year population, which is lacking in the present study. Although it is somewhat underestimate of the true incidence, even then it has the implication from preventive and management point of view, for it still describes the risk of acquiring ocular trauma in a defined population in one year.

A nearly similar incidence (4.9 per 1000 per year) was reported in Baltimore study ${ }^{\mathbf{1}}$. However, a much lower incidence (1.9 per 1000 per year) for any medically treated injury was reported in Whites compared to that in Blacks (4.4 per 1000 per year) aged 45 years and older. The rate in New England was 2.2 per 1000 per year for the same age group in a predominantly White population ${ }^{\mathbf{3 0}}$ indicating that Blacks carry higher risk of sustaining ocular trauma than their White counterparts living in the same geographical territory. In this study 13(7.78\%) received trauma during the month preceding the interview which is almost half $(15.18 \%)$ than that of Delhi study ${ }^{24}$.

Blindness: Blinding episode following ocular trauma in the present study was 10 out of 
$167(5.98 \%)$ cases and $0.12 \%$ among sampled population which is lower than that reported in studies by Vats et $\mathrm{al}^{\mathbf{2 4}}(0.3 \%)$, Nirmalan et $\mathrm{al}^{\mathbf{1 6}}$ $(0.5 \%)$, and in Dandona et $\mathrm{al}^{6}(0.6 \%)$. Among the 10 cases of blindness from ocular trauma, $5(55.5 \%)$ were caused due to phthisis bulbi, $3(33.3 \%)$ due to corneal scar, 1(11.1) traumatic cataract and another $1(11.1 \%)$ due to surgical anophthalmia in one eye. The Andhra Pradesh study ${ }^{10}$ reveals that among the 39 cases of blindness from ocular trauma, $13(33.3 \%)$ eyes had traumatic cataract, another $13(33.3 \%)$ had traumatic corneal scars, $8(20.5 \%)$ were phthisical, 4(10.3\%) had traumatic optic atrophy, and $1(2.6 \%)$ had surgical anophthalmia. The current study showed phthisis bulbi as the prime cause of traumatic blindness, while traumatic cataract and corneal ulcers were prime causes in Andhra Pradesh study ${ }^{10}$. If the present study findings are extrapolated for 112.2 million (72\%) rural population of Bangladesh ${ }^{\mathbf{3 3}}$ there might have $2,244,000$ people with at least one episode of ocular trauma and 134,640 of them are blind of one eye due to trauma. To them 695,640 people with new occurrence of ocular trauma are being added each year. These figures indicate that effective strategies are required to reduce the incidence of ocular trauma and the blindness resulting from it.

\section{Demographic characteristics and ocular trauma:}

The role of two demographic characteristics, age and gender, is of utmost importance in all studies. Dandona et $\mathrm{al}^{\mathbf{6}}$ stated that men were 2.5 times as likely to have ocular trauma as women. In a study in Australia, ${ }^{8}$ ocular trauma in men was 3.5 times higher than that in women. In a systematic review of global eye injuries by $\mathrm{Negral}^{\mathbf{9}}$ the male to female ratio for ocular trauma was stated as low as 2 and as high as 8.5 in Iceland. In any event, all reports indicate that men are at higher risk of ocular injuries, and this can mainly be attributed to occupational differences and men's involvement with more risky tasks than women. Three tertiary hospital-based studies ${ }^{\text {20-22 }}$ in Dhaka, Bangladesh reported male-female ratio for ocular trauma to be $8: 2$. The odds of ocular trauma in men in different studies ${ }^{\mathbf{7 , 2 4 , 2 6}}$ were more than 2 times than those in women and more than 4-fold in Beaver Dam study ${ }^{4}$. Contrary to these findings this study demonstrated a female predominance with male to female ratio being roughly 4:5. This days females in rural Bangladesh, in addition to their household works, participate in agriculture work, more so during harvesting seasons which may explain the higher prevalence of ocular trauma in females.

In the present study the peak age episode of ocular injury was $3^{\text {rd }}$ decade of life. Thereafter the vulnerability for ocular injury decreases with increasing age. The participants having ocular injury was generally older compared to those without ocular injury and the risk of getting ocular trauma was almost 4 times higher among participants 30 years and older compared to those below 30 years old. The median age at trauma was $40.5 \pm 1.5$ years (range 5-82 years). In Andhra Pradesh study ${ }^{6}$ the mean age of persons reporting a history of ocular trauma was $40.2 \pm 15.6$ years (range, 1-95 years) which is quite consistent with present study. Age at trauma did not differ significantly between gender $(p=0.182)$. In Aravind's study $^{7}$ the mean age of persons at reporting a history of ocular trauma was $52.6 \pm 9.4$ years (range: 40-85 years). However, in Delhi study $^{24}$ the mean age of the participants was $28.2 \pm 14.6$ years and the mean age at which ocular trauma was sustained was much lower $(24.2 \pm 13.5$ years).

In terms of education over one-quarter $(28.7 \%)$ of the subjects with ocular injury were illiterate with odds illiterates and subjects having no formal education being 1.7 times higher than that of literates $(p=<0.001)$. This report is almost comparable with Andhra Pradesh study ${ }^{6}$ and Aravind study ${ }^{7}$ which revealed incidence of trauma to be significantly greater among illiterate subjects $(p=<0.0001)$. Delhi study ${ }^{24}$ however, did not corroborate the reported decreased risk of ocular trauma in literates. In this study housewives comprised nearly $40 \%$ of the subjects and farming and agriculture labor $27 \%$. In rural Bangladesh agriculture is the main occupation and housewives are engaged in agriculture at home and field. In terms of settings in which ocular trauma occurred home alone constituted $55 \%$ and the next predominant setting was agriculture field (21.6\%). In Aravind study ${ }^{7}$ most common setting of ocular trauma was agricultural field (46.9\%) and over onequarter $(26.7 \%)$ of all ocular traumas occurred in a domestic setting which although is inconsistent with the findings of the present study, favor the findings of Nepal study ${ }^{\mathbf{3 4}}$, where domestic or agricultural injuries being the most common. In the present study farmers, agriculture labors, housewives and participants engaged in household works together were more than 1.8 times as likely to receive ocular trauma as the participants engaged in industrial sector, service, business and others $(\mathrm{p}=0.005)$. The Andhra Pradesh study ${ }^{4}$ reports that occupational hazards remain the most common cause of ocular injuries, as was evident by previously published reports ${ }^{\mathbf{4 , 1 1}}$. Trauma from vegetable matter was the most common cause in the rural population which reflects agriculture being the primary occupation at risk of ocular 
trauma. In the present study marriage was also found to be a determinant of ocular trauma with married population being at 3.7 times higher risk of sustaining the trauma than their non-married counterparts or participants below marriageable age $(p<0.001)$. We could not find any study report in which marriage was described as a risk factor for ocular trauma. As conflict between spouses followed by violence is common in every society, it is not unlikely that married subjects will have higher risk of ocular injury along with other bodily injuries.

Trauma related profile: Evaluating the last episode of trauma, $2.4 \%$ gave history of trauma in both eyes and $52.1 \%$ and $45.5 \%$ in right and left eyes respectively. Single episode of trauma was reported by $82 \%$ of the participants, two episodes by $15 \%$ and three or more by $3 \%$ which are more or less consistent with the findings of Andhra Pradesh study $^{6}$ where $1 \%$ had trauma in both eyes, single episode of trauma in $82.8 \%$ and two episodes of trauma in $3.2 \%$. It is reveled from Beaver Dam study $^{4}$ that a person reporting a history of ocular trauma in his or her lifetime had a three times higher risk of experiencing subsequent ocular trauma in the next 5 years. In addition, if both eyes had been injured previously, the risk of subsequent trauma increased to 5 times. This reflects that there exist a high-risk or "injury prone" groups in whom health education or preventive programs may be highly effective in reducing the incidence of ocular trauma.

Hospital stay: In this study $12.4 \%$ (18 out of 145 ) cases who received some sorts of treatment following trauma needed hospitalization for better care with mean duration of stay $7.6 \pm 1.6$ days. Most of the injured eyes had normal vision before trauma as informed by the respondents. However, at the time of interview two-thirds $(65.9 \%)$ of the injured eyes exhibited normal visual acuity, $18 \%$ impaired and $10.7 \%$ severely impaired vision and some $5 \%$ were functionally blind. Over half $(53 \%)$ informed job abstinence due to ocular trauma and the median wage loss due to illness was 10 days. Nonetheless, the cost of hospitalization associated with manpower involvement (both administrative and nonadministrative) to provide services to the patients during their hospital stay and opportunity cost due to wage loss and resulting disability provide a rough estimate of how far-reaching effect these traumas can produce on family and society. Studies from the Tehran ${ }^{\mathbf{2 6}}$, United States ${ }^{\mathbf{3 5}}$, Australia ${ }^{\mathbf{3 6}}$ and the Beaver Dam ${ }^{4}$ study reported admission rates of $2.4 \%, 2.5 \%, 4.9 \%$ and $8.9 \%$, respectively following ocular trauma. However the Beaver Dam study finding was found closer to the present study. All other studies presented much lower hospital admission rates.

Care seeking behavior following trauma:

Poor utilization of eye care among rural populations has been attributed to the lack of available and affordable eye care services. Of the 167 ocular trauma cases $145(86 \%)$ received some sorts of care after trauma. Median time lapsed to seek first treatment was 5 days (range: 1 and 360 days) and that to receive care of a specialist was 18 days (range: 1-480 days). In terms of nature of treatment received, self-treatment and treatment sought over the counter formed the main bulk (45.5 and $42.1 \%$ respectively), village allopath and homeopath quacks treatment were 22.8 and $12.4 \%$ respectively. Over one-quarter $(25.5 \%)$ visited an eye-specialist while $19.3 \%$ sought treatment from graduate doctors, because the clusters were nearer an NGO clinic where graduate doctors are often available. Only $6.9 \%$ sought treatment from Kabiraz. In Baltimore and Aravind studies 1,7, 72\% and $75 \%$ of those with a history of ocular injuries sought treatment respectively and it is encouraging in the later study that $57.8 \%$ primarily received it from an ophthalmologist. Consistent with the findings of the present study majority $(86.5 \%)$ of Andhra Pradesh Study ${ }^{6}$ subjects sought treatment for eye injury with $43.1 \%$ from an eye specialist. Very few $(0.8 \%)$ received treatment from traditional healers. The acute nature of ocular injuries and the associated symptoms may act as driving force to seek eye care from the eye specialists outright. As much of the trauma-related blindness is preventable through the use of simple appropriate ocular protection device and appropriate treatment following trauma, people should be made aware to use eye protecting glass at workplace and receive appropriate treatment as soon as trauma occurs. In this study $96 \%$ the people who gave a history of ocular trauma admitted that they did not use any eye protection device at the time of trauma which is a cause concern from public health point of view and leaves scope for behavior change communication.

Strengths and limitations: However, like any other scientific studies, the present study also has some strengths and limitations. The following strengths and limitations deserve mention. Door-to-door enumeration and high response rates from subjects who were randomly selected is a major strength of this study. It is possible that the prevalence of trauma reported in this study may be an underestimate, because much of the information on trauma was collected by recall, and people may not have reported minor injuries or injuries sustained at younger ages, especially during childhood. 
Conclusion: The findings of study suggest that point-prevalence of ocular trauma in rural population is around $2 \%$ with blunt objects commonly causing the trauma and one in every 16 trauma-hit case undergo blind. Addressing blindness from ocular trauma, should, therefore, be a priority for eye care programs in rural Bangladesh.

\section{Acknowledgement}

My gratitude to the Gonoshasthaya Kendra(GK) for helping in collecting data and I am grateful to Prof. Md. Shafiqul Islam, Department of Ophthalmology, Bangabandhu Sheikh Mujib Medical University, Dhaka \& Prof. Dr. M A Mannan, Institute of Biological Sciences, University of Rajshahi, Rajshahi for sincere guidance. This study was funded by BMRC under Research and Development Project HNPSP during 2011-2012.

\section{References}

1. Katz J, Tielsch JM. Lifetime prevalence of ocular injuries from the Baltimore Eye Survey. Arch Ophthalmol 1993;111:1564-8.

2. Schein OD, Hibberd P, Shingleton BJ, Kunzweiler T, Frambach DA, Seddon JM. The spectrum and burden of ocular injury. Ophthalmology 1988;95:300-5.

3. McCarty CA, Fu CL, Taylor HR. Epidemiology of ocular trauma in Australia. Ophthalmology 1999;106:1847-52.

4. Wong TY, Klein BEK, Klein R. The prevalence and 5Year incidence of ocular trauma. The Beaver Dam Eye Study. Ophthalmology 2000;107:2196-202.

5. Glynn RJ, Seddon JM, Berlin BM. The incidence of eye injuries in New England adults. Arch Ophthalmol 1988;106:785-9.

6. Dandona L, Dandona R, Srinivas M, John RK, McCarty CA, Rao GN. Ocular trauma in an urban population in southern India: The Andhra Pradesh Eye Disease Study. Clin Exp Ophthalmol 2000; 28(5): 350-6.

7. Nirmalan PK, Katz J, Tielsch JM, Robin AL, Thulasiraj RD, Krishnadas R, Ramakrishnan R. Ocular trauma in a rural south Indian population: The Aravind Comprehensive Eye Survey. Ophthalmology 2004; 111: $1778-81$

8. Wong TY and Tielsch JM. A. Population-Based Study on the Incidence of Severe Ocular Trauma in Singapore. Am J Ophthalmol 1999; 128(3); 345-51.

9. Negrel AD. Magnitude of eye injuries worldwide. $J$ Community Eye Health 1997; 10: 49-3.

10. Krishnaiah S, Nirmalan PK, Shamannah BR, Srinivas M, Rao GN, Thomas R. Ocular trauma in rural area population of Southern India. Ophthalmology 2006; 113(7): 1159-64.
11. Koval R, Teller J, Belkin M, Romem M, Yanko L, Savir H. The Israeli Ocular Injuries Study. A nationwide collaborative study. Arch Ophthalmol 1988;106:776-80

12. Schein OD, Hibberd PL, Shingleton BJ, Kunzweiler T, Frambach DA, Seddon JM. The spectrum and burden of ocular injury. Ophthalmology 1988;95:300-5.

13. Brilliant GE. Epidemiology of blindness in Nepal. Report of the 1981 Nepal Blindness Survey. Chelsea, MI: Seva Foundation; 1988:377-417.

14. Upadhyay MP, Karmacharya PC, Koirala S, Tuladhar $\mathrm{N}$, Bryan LE, Smolint G. Epidemiologic characteristics, predisposing factors, and etiologic diagnosis of corneal ulceration in Nepal. Am $J$ Ophthalmol 1991; 111:92-9.

15. Mohan M. National Survey of Blindness-India (19861989), Summary Results NPCB-WHO report. New Delhi: Ministry of Health and Family Welfare, Government of India; 1992.

16. Nirmalan PK, Thulasiraj RD, Maneksha V Rahmathullah R, Ramakrishnan R, Padmavathi A. A population based eye survey of older adults in Tirunelveli district of south India: blindness, cataract surgery and visual outcomes. Br J Ophthalmol 2002; 86:505-12.

17. Dandona L, Dandona R, Naduvilath TJ. Burden of moderate visual impairment in an urban population in southern India. Ophthalmology 1999;106:497-504.

18. Dandona L, Dandona R, Srinivas M, Dandona R, Srinivas M, Giridhar P,Vilas K, Mudigonda N, Prasad,Rajesh K, John,Catherine A. McCarty, and Gullapalli N, Rao. Blindness in the Indian state of Andhra Pradesh. Invest Ophthalmol Vis Sci 2001; 42: 908-16.

19. Rahman MM. Paediatric Ocular Injury in Bangladesh; Trans Ophthal Soc Bang.1983;XI: 74-9.

20. Islam MN, Hossain A. Ocular injuries, prospective study \& Prevention. Trans Ophthal Bang 2001; 28(2): 44-6.

21. Rahman MS, Haider G, Uddin MS, Hossain SM, Jalil A, Haq DMN. Incidence and pattern of ocular injury attended at National Institute of Ophthalmology \& Hospital. The year 1991-2000. Trans Ophthal Soc Bang 2001;28(1):78-81.

22. Mohiuddin AA, Hossain AF, Khan MRA, Bhuya SI, Ishtiaque. Incidence, Pattern and Complications of Major Ocular Injuries Admitted in Unit-4 at NIO\&H Dhaka During The Year 2004;Ophthal Soc Bang Trans:32(2):104-6.

23. Quayum MA, Akanda AH. Pattern of Ocular Trauma Admitted in Tertiary Hospital; Mymensingh Med. J 2009 Jan; 18(1):1-6.

24. Vats S, Murthy GVS, Chandra M, Gupta SK, Vashist $\mathrm{P}$, Gogoi M. Epidemiological study of ocular trauma in an urban slum population in Delhi, India. Indian $J$ Ophthalmol 2008; 56(4):313-6.

25. Loon SC, Tay WT, Saw SM, Wang JJ, Wong TY. Prevalence and risk factors of ocular trauma in an 
urban south-east Asian population: the Singapore Malay Eye Study. Clin Experiment Ophthalmol 2009;37(4):362-7.

26. Hashemi H, Khabazkhoob M, Mohammad K, Fotouhi A, History of Ocular Trauma in Tehran Population: Tehran Eye Study. Iranian Journal of Ophthalmology 2011;23(3):43-9.

27. Thylefors B. Epidemiological patterns of ocular trauma. Aust N Z J Ophthalmol 1992;20(2):95-8.

28. Porter K, Scully C, Theyer Y, Porter S. Occupational injuries to dental personnel. J Dent 1990;18(5):258-62.

29. Vasu U, Vasnaik A, Battu RR, Kurian M, George S. Occupational open globe injuries. Indian J Ophthalmol 2001;49(1):43-7.

30. Glynn RJ, Seddon JM, Berlin BM. The incidence of eye injuries in New England adults. Arch Ophthalmol 1988;106:785-9.

31. Klopfer J, Tielsch JM, Vitale S, Lai-Chu See, Canner J. Ocular trauma in the United States, eye injuries resulting in hospitalization, 1984-1987. Arch Ophthalmol 1992;110:838-42.

32. Morris RE, Witherspoon CD, Helms HA, Feist RM, Byrne JB. Eye injury registry of Alabama (preliminary report): demographic and prognosis of severe eye injury. South Med J. 1987;80:810-6.

33. CIA fact sheet for Bangladesh, 2011.

34. Khatry SK, West KP Jr, Katz J, LeClerq SC, Pradhan EK, Wu LS, Thapa MD, Pokhrel RP.The epidemiology of ocular trauma in rural Nepal. Br $J$ Ophthalmol 2004;88:456-60.

35. McGwin G Jr, Xie A, Owsley C. Rate of eye injury in the United States. Arch Ophthalmol 2005; 123(7): 970-6.

36. Thompson CG, Griffts RK, Nardi W, Tester MP, Noble MJ, Cottee L. Penetrating eye injuries in rural New South Wales. Aust N Z J Ophthalmol 1997; 25:37- 41 